\title{
A metrological approach to improve accuracy and reliability of ammonia
}

\section{measurements in ambient air}

3 Andrea Pogány ${ }^{1}$, David Balslev-Harder ${ }^{2}$, Christine F. Braban ${ }^{3}$, Nathan Cassidy ${ }^{4}$, Volker Ebert ${ }^{1}$, Valerio Ferracci ${ }^{4{ }^{4}}$,

4 Tuomas Hieta ${ }^{5, * *}$, Daiana Leuenberger ${ }^{6}$, Nicholas A. Martin ${ }^{4}$, Céline Pascale ${ }^{6}$, Jari Peltola ${ }^{5}$, Stefan Persijn ${ }^{7}$, Carlo

5 Tiebe $^{8}$, Marsailidh M. Twigg ${ }^{3}$, Olavi Vaittinen ${ }^{9}$, Janneke van Wijk ${ }^{7}$, Klaus Wirtz $^{10}$, Bernhard Niederhauser $^{6}$

${ }^{1}$ Physikalisch-Technische Bundesanstalt (PTB), Bundesallee 100, 38116 Braunschweig, Germany

${ }^{2}$ Dansk Fundamental Metrologi A/S (DFM), Matematiktorvet 307, DK-2800 Kgs. Lyngby, Denmark

${ }^{3}$ Natural Environment Research Council, Centre for Ecology \& Hydrology (NERC), EH26 OQB, Bush Estate,

Penicuik, Midlothian, United Kingdom

${ }^{4}$ National Physical Laboratory (NPL), TW11 OLW, Teddington, Middlesex, United Kingdom

${ }^{5}$ VTT Technical Research Centre of Finland Ltd, Centre for Metrology (VTT), P.O. Box 1000, FI-02044 VTT, Finland

${ }^{6}$ Federal Institute of Metrology (METAS), Lindenweg 50, 3003 Bern-Wabern, Switzerland

${ }^{7}$ Dutch Metrology Institute (VSL), Thijsseweg 11, 2629 JA Delft, The Netherlands

${ }^{8}$ BAM Federal Institute for Materials Research and Testing, Unter den Eichen 87, 12205 Berlin, Germany

${ }^{9}$ University of Helsinki, Department of Chemistry, A.I. Virtasen aukio 1, P.O. Box 55, 00014, Helsinki, Finland

${ }^{10}$ Umweltbundesamt (UBA), Wörlitzer Platz 1, 06844 Dessau-Roßlau, Germany

\section{Keywords}

ammonia in ambient air, traceability, reference gas standards, optical transfer standard, validation and testing infrastructure

\section{Abstract}

The environmental impacts of ammonia $\left(\mathrm{NH}_{3}\right)$ in ambient air have become more evident in the recent decades, leading to intensifying research in this field. A number of novel analytical techniques and monitoring instruments have been developed, and the quality and availability of reference gas mixtures used for the calibration of measuring instruments has also increased significantly. However, recent inter-comparison measurements show significant discrepancies, indicating that the majority of the newly developed devices and reference materials require further thorough validation. There is a clear need for more intensive metrological research focusing on quality assurance, intercomparability and validations. MetNH3 (Metrology for ammonia in ambient air) is a three-year project within the framework of the European Metrology Research Programme

34 (EMRP), which aims to bring metrological traceability to ambient ammonia measurements in the 0.5 $500 \mathrm{nmol} / \mathrm{mol}$ amount fraction range. This is addressed by working in three areas: 1) improving accuracy and 
stability of static and dynamic reference gas mixtures, 2) developing an optical transfer standard and 3) establishing the link between high-accuracy metrological standards and field measurements. In this article we describe the concept, aims and first results of the project.

\section{Introduction}

The average background concentration of ammonia in ambient air is in the range of $0.1-5 \mathrm{nmol} / \mathrm{mol}$ $(0.1-5 \mathrm{ppb})$, and it increases up to the order of $100 \mathrm{nmol} / \mathrm{mol}$ in the direct vicinity of agricultural facilities or activities. Despite the low amount fractions, measuring ammonia in ambient air is a key issue in environmental science. Ammonia can have harmful effects on ecosystems and biodiversity by affecting the acidity of natural waters and soils, providing excess nitrogen input to ecosystems[1], and on human health through influencing secondary aerosol formation [2][3]. Critical levels of ammonia have been defined for sensitive ecosystems [4]. These levels are established by experimental evidence as $1 \mu \mathrm{g} / \mathrm{m}^{3}$ ( $1.4 \mathrm{nmol} / \mathrm{mol}$, annual mean concentration) for ecosystems dominated by lichens and bryophytes and $3 \mu \mathrm{g} / \mathrm{m}^{3}(\sim 4.2 \mathrm{nmol} / \mathrm{mol})$ for other ecosystems.

The first international regulation to control ammonia emissions was the "multi-pollutant" protocol to Abate Acidification, Eutrophication and Ground-level Ozone (called the Gothenburg protocol, agreed in November 1999 [5]) under the Convention on Long-Range Transboundary Air Pollution (CLRTAP) signed by Central and Eastern European countries, the EU, the United States and Canada. Annex IX of the protocol defines the measures to control ammonia emissions from agricultural sources and reduce emissions under the emission ceilings determined for each country by 2010. A revision of the Gothenburg protocol was settled in 2012 [6] to continue emission reductions until 2020. In the European Union the Gothenburg Protocol is implemented through the National Emissions Ceiling Directive (NEC, 2001/81/EC, [7]). In addition national and local ammonia levels are also relevant for EU Habitats Directive [8].

The European Monitoring and Evaluation Programme (EMEP [9]), directed by the United Nations Economic Commission for Europe (UNECE) was founded to support governments and subsidiary bodies under the CLRTAP convention. A broad network of scientists and experts contribute to the collection, analysis and reporting of emission data. Further national monitoring networks with higher spatial resolution (e.g. Measuring Ammonia in Nature (MAN [10]) Network in the Netherlands, and the National Ammonia Monitoring Network (NAMN) in the UK) provide additional data to assess ambient ammonia concentrations and trends. Besides these long-term monitoring activities, shorter measurement campaigns with higher temporal resolution are organized as well to address specific questions [11][12][13]. Countries currently adopt a variety of approaches; there is no European standard for ammonia monitoring.

Despite the clear need set by regulations, the majority of analytical techniques, which underpin or validate ammonia emission estimates lack thorough uncertainty analyses and quality assurance. Measurements are challenging due to the low concentrations of ammonia in ambient air and the relatively high concentrations of potential interfering atmospheric components. Furthermore, the highly adsorptive properties of gas-phase ammonia raise difficulties in the construction of sampling inlets for analyzers, as well as for the preparation of reference gas mixtures. Inter-comparison measurements have shown significant discrepancies between different analytical methods [11], and the agreement even between reference materials provided by National 
MetNH3 [15] (Metrology for ammonia in ambient air) is a three-year project that started in June 2014 within the framework of the European Metrology Research Programme (EMRP). The project aims to improve comparability and reliability of ambient ammonia measurements via the development of metrological standards. These standards include both reference gas mixtures and standard analytical methods with the aim of providing traceable ammonia amount fractions in the environmentally relevant range of $0-500 \mathrm{nmol} / \mathrm{mol}$.

Traceability is a property of the measurement results (in this case the ammonia amount fractions), meaning that the results can be related to the primary metrological standards (in the end to the definition of the SI units) through an unbroken chain of calibrations. This chain of calibrations, linking the measurement results to the highest metrological standards, ensures their reliability. Furthermore, within the chain of calibrations, the measurement uncertainty introduced by each step is carefully determined, in compliance with the guidelines of the ISO-Guide 98-3 "Evaluation of Measurement Data - Guide to the Expression of Uncertainty in Measurement" (GUM) [16]. These well-defined uncertainties and the uniform uncertainty assessment ensure comparability of measurement results originating from different sources.

In this article we first give an overview on the topics studied in the MetNH3 project (Section 2), thereafter we show selected results in two fields: studying adsorption losses in static and dynamic systems (Section 3.1), and achieving traceability in the spectroscopic detection of ammonia (Section 3.2).

Parts of this work have been presented at the International Congress of Metrology (CIM 2015, held between $21^{\text {st }}$ and $25^{\text {th }}$ September 2015 in Paris, France) [17].

\section{Topics studied in the MetNH3 project}

This section describes the main topics studied in the MetNH3 project. The first topic is the preparation of reference gas mixtures with the aim of achieving traceability and reducing uncertainties in both static reference gas mixtures prepared in cylinders (Section 2.1) and reference gases provided by dynamic generators (Section 2.2). The second topic deals with optical measurement methods (Section 2.3) with the aim of developing an optical transfer standard, i.e., a spectrometer that is suitable for the calibration and validation of other instruments. A commercial extractive spectrometer and a self-developed sampling-free spectrometer are examined within the project from a metrological point of view and their applicability as optical transfer standards is evaluated. Selected reference gas mixture(s) and optical transfer standard(s) will be used for the third main objective, the dissemination of the results to field measurement techniques through intercomparison and validation experiments. Two test facilities are described in Section 2.4, which will serve as the infrastructure for these experiments. A further important point, the study of adsorption of ammonia on different material surfaces (Section 2.5) plays a role in all afore mentioned activities.

The project partners are involved in the different topics as follows (see explanation of the abbreviations in

106 the affiliations): VSL, NPL, METAS, BAM and UH are developing the reference gas mixtures and performing adsorption studies, PTB, DFM, MIKES-VTT and NERC are working on the standard optical methods for ammonia detection, the two test facilities are being developed at UBA and NPL and all partners are involved in the dissemination of the results to field measurements.

\subsection{Static reference gas mixtures in cylinders}


Ammonia reference gas mixtures with amount fractions down to a few $\mu \mathrm{mol} / \mathrm{mol}$ can be produced following the approach for gravimetric preparation of gas mixtures (as detailed in ISO 6142 [18]). Although this amount fraction range is at least two orders of magnitude higher than typical ambient values, these mixtures offer a simple and widely used tool for the calibration of analytical instrumentation when combined with an appropriate dilution system. Figure 1 shows an experimental set-up, which allows calibration over a range of ammonia amount fractions of typically one to two orders of magnitude, depending on the flow rates of the reference gas mixture and the diluting matrix gas.

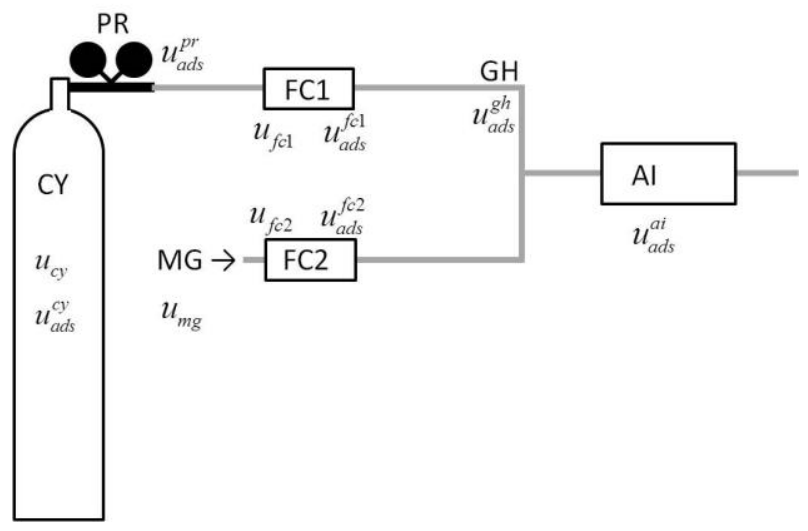

Figure 1: Typical set-up for the calibration of an analytical instrument using a gas mixture in a cylinder, and usual uncertainty components.

$121 \mathrm{CY}$ : gas cylinder containing the reference gas mixture, PR: pressure regulator, GH: gas handling tubes, MG: ammonia-free matrix gas used to dilute the mixture, FC1 and FC2: flow control units, Al: analytical instrument to be calibrated. $u_{c y}$ : uncertainty in the ammonia amount fraction in the gas mixture, $u_{f c 1}$ and $u_{f c 2}$ : uncertainty in the gas flow rates set by the flow control units, $u_{m g}$ : uncertainty added by the presence of ammonia impurities in the matrix gas; and uncertainties caused by adsorption-desorption processes $u_{a d s}^{c y}$ : in

126 the cylinder, $u_{a d s}^{p r}$ : in the pressure regulator, $u_{a d s}^{f c 1}$ and $u_{a d s}^{f c 2}$ : in the flow control units, $u_{\text {ads }}^{g h}$ : in the gas handling tubes and $u_{a d s}^{a i}:$ in the analytical instrument.

Typical uncertainties of ammonia amount fractions in commercial reference gas mixtures are $5-10 \%$, while certified reference gas mixtures provided by national metrology institutes (NMIs) often achieve an uncertainty (expanded uncertainty, $k=2$, referring to $95 \%$ confidence level) down to $1 \%$. The stability of the gas mixtures is usually guaranteed by the manufacturer for 12-24 months. These uncertainties are appropriate for certain applications; however, uncertainties added by the user while diluting the mixture are not negligible and must be accounted for. Uncertainties added by the accuracy of the flow control units (e.g. mass flow controllers or critical orifices) are typically in the range of $1 \%$, provided that the flow control units are regularly calibrated. Ammonia impurities in most matrix gases are in the sub-nmol/mol range. As an example the ammonia impurity in the matrix gas used in our experiments was found to be $0.05 \pm 0.05 \mathrm{nmol} / \mathrm{mol}$. This value is negligible, when preparing mixtures in the amount fraction range above $20 \mathrm{nmol} / \mathrm{mol}$, but might be the dominant uncertainty component at lower amount fractions. For comparison, this matrix gas impurity has a relative contribution of $2 \%$ to the final $\mathrm{NH}_{3}$ amount fraction uncertainty, when diluting a mixture of 
141 cylinder, and $1 \%$ relative uncertainty of the flow rates), and a relative contribution around $90 \%$ when diluting

142 the same mixture to $1 \mathrm{nmol} / \mathrm{mol}$. Artefacts introduced by the adsorption-desorption processes on the surfaces

143 of the pressure reducer, sampling lines, flow control units and the analytical instrument itself have to be 144 considered and minimized as well. The magnitude of this effect is highly dependent on the experimental 145 conditions; in the case of a properly designed gas handling system this uncertainty component is negligible,

146 while even a short tubing or device constructed of an adsorbing material might lead to losses up to $30 \%$.

147 The efforts of the gas metrology community in the field of gravimetric preparation and certification of gas 148 mixtures are aptly summarised in the report of the international key comparison CCQM-K46 [14]. In this 149 comparison exercise, mixtures with nominal amount fraction over the range of $30-50 \mu \mathrm{mol} / \mathrm{mol}$ were 150 distributed to the participating NMIs, who in turn certified these mixtures using their own in-house reference 151 standards and methods. Whilst a certain level of agreement between the different methods used to certify the 152 mixtures could be observed, the overall discrepancies were also obvious. Despite of the fact that the stated 153 uncertainties were typically below $2 \%$, differences up to $5 \%$ have been found between the results obtained by 154 different methods. This disagreement was attributed to a number of reasons, including the different cylinder 155 passivation techniques used by the participating NMIs to produce their own reference mixtures, and the 156 different analytical techniques used to perform the analysis. For instance, it was discussed that the dynamic 157 preparation by permeation and subsequent dilution where a continuous gas flow is maintained over several 158 hours compared against measurements on gas cylinders done over much shorter periods of time can lead to 159 discrepancies due to adsorption effects. The lack of consensus amongst NMIs may result in poor instrument 160 calibration and would affect the comparability of national measurement networks. The MetNH3 project aims 161 to achieve uncertainties below $1 \%$ in reference gas mixtures prepared at the $10 \mu \mathrm{mol} / \mathrm{mol}$ and $100 \mu \mathrm{mol} / \mathrm{mol}$ 162 level. Gas mixtures are prepared by different project partners, in cylinders from different manufacturers, with 163 different surface passivation treatments. Besides decanting studies to evaluate adsorption losses, stability of 164 the gas mixtures will be monitored during the lifetime of the project. The results obtained so far are presented 165 in Section 3.1. A further key comparison (CCOM K-117) is also planned and will be organized by VSL and NIST in 166 2016-2017, where individual project partners will participate.

\subsection{Dynamic reference gas generators}

An alternative to reference gas mixtures in cylinders is offered by dynamic reference gas generators, which provide the opportunity to prepare reference gas mixtures in the environmentally relevant amount 170 fraction ranges $(0.5-500 \mathrm{nmol} / \mathrm{mol})$. State of the art commercially available mobile gas mixture generators use 171 a method based on the specific temperature-dependent permeation of the reference substance through a 172 membrane into a flow of purified matrix gas, e.g., nitrogen or air, as described in the ISO 6145-10 standard 173 [19]. These devices consist of a temperature controllable permeation chamber, in which a reference substance, 174 stored in a permeation device, is placed. The substance permeating through the membrane into the carrier gas 175 (matrix gas) stream causes a continuous mass loss in the permeation device, which can be quantified by 176 periodic weighting. By precise measurement of the temperature dependent mass loss over time as well as of 177 the gas flow, the amount fraction of the analyte added to the carrier gas can be calculated. If necessary, the 
obtained gas mixture is further diluted to the required amount fraction range by the application of mass flow controllers or critical orifices.

180 Permeation is a widely used approach for the dynamic generation of gas mixtures of different analytes in the amount fraction range of $\mathrm{nmol} / \mathrm{mol}$ to $\mu \mathrm{mol} / \mathrm{mol}$; devices from several manufacturers are commercially available [20][21][22][23] and used for the calibration of on-line analysers in laboratories and in the field. However, despite of their widespread use triggered by their flexibility, ease of operation and reliability, from the metrological point of view, commercially available devices show one significant deficiency: they are not purpose-built for the generation of reference gas mixtures traceable to SI-standards. They lack traceability foremost in temperature and flow measurements but also in the parameters controlling the permeation rate, i.e., time, mass and pressure which impedes the precise assessment of an uncertainty of the generated gas. We estimate the typical relative expanded uncertainty of $\mathrm{NH}_{3}$ amount fractions in gas mixtures provided by commercial permeation generators to be $10-20 \%$.

MetNH3 aims to generate ammonia CRM according to ISO/IEC Guide 99:2007 [24] in ambient $\mathrm{NH}_{3}$ amount fractions of $0.5-500 \mathrm{nmol} / \mathrm{mol}$ with a relative expanded uncertainty below $3 \%$. Two different mobile reference gas generators are developed with the purpose of becoming essential for the calibration of on-site analytical instrumentation of e.g. national monitoring networks. Due to strong demand and to promote technical diversity, two portable gas generators are developed within the project. The devices have a different design and comprise of different individual parts unless there is technical superiority of one supplier. Amount fractions as low as $0.5 \mathrm{nmol} / \mathrm{mol}$ can only be generated when the base mixture from the permeation chamber is further diluted by at least two additional dilution steps. For this purpose, a commercially available permeation oven has been combined with thermal mass flow controllers. equation:

where $P R(T) \equiv \Delta m(T) / \Delta t$ is the permeation rate, i.e., the temperature-dependent mass loss $(\Delta m(T))$ of the permeation device per unit time $(\Delta t), K=V_{M} / M_{N H_{3}}$ is the ratio of the molar volume of gas $\left(V_{M}\right)$ and the molar mass of ammonia $\left(M_{N H_{3}}\right), Q_{1}$ is the flow rate through the permeation chamber, $D_{1}$ and $D_{2}$ are the dilution ratios in the two additional dilution steps after the permeation chamber (determined from the flow rates through the mass flow controllers used for the dilution) and $x_{C G}$ is the residual ammonia amount fraction in the carrier gas (matrix gas). In order to generate traceable ammonia amount fractions, all input parameters needed for the calculation of the ammonia amount fraction have to be traceable to NMI standards. This requires the accessibility of the temperature sensor in the permeation oven, mass flow and pressure controllers and the permeation device for calibration purposes. In order to achieve the ambitious aim of

211 expanded uncertainty below $3 \%$, precision and stability of the individual components have to be assured. As

212 an example, the individual expanded uncertainties of the two most important parameters, i.e., the permeation

213 rate $(P R(T))$ and the dilution rates $\left(D_{1}\right.$ and $\left.D_{2}\right)$ must not exceed $1.7 \%$ and $0.6 \%$, respectively. The low 
214 uncertainty in the permeation rate can be achieved by weighting the permeation device using a magnetic 215 suspension balance where the temperature dependent mass loss per unit time can be monitored continuously 216 and under highly stable conditions. Considerable uncertainty, particularly at lower amount fractions is added 217 by residual $\mathrm{NH}_{3}$ in the carrier gas (approximately $0.05 \pm 0.05 \mathrm{nmol} / \mathrm{mol}$ ).

\subsection{Spectroscopic detection of ammonia}

During the construction of a spectrometer the first crucial point is the spectral line selection. Ambient ammonia amount fraction is typically one to seven orders of magnitude lower than amount fractions of other atmospheric components (most importantly water vapour, carbon dioxide, ozone and methane), which results in severe spectral interference and cross sensitivities. Figure 2 gives an overview of the infrared spectrum of ammonia and common atmospheric components (data taken from the HITRAN 2012 database [25]).

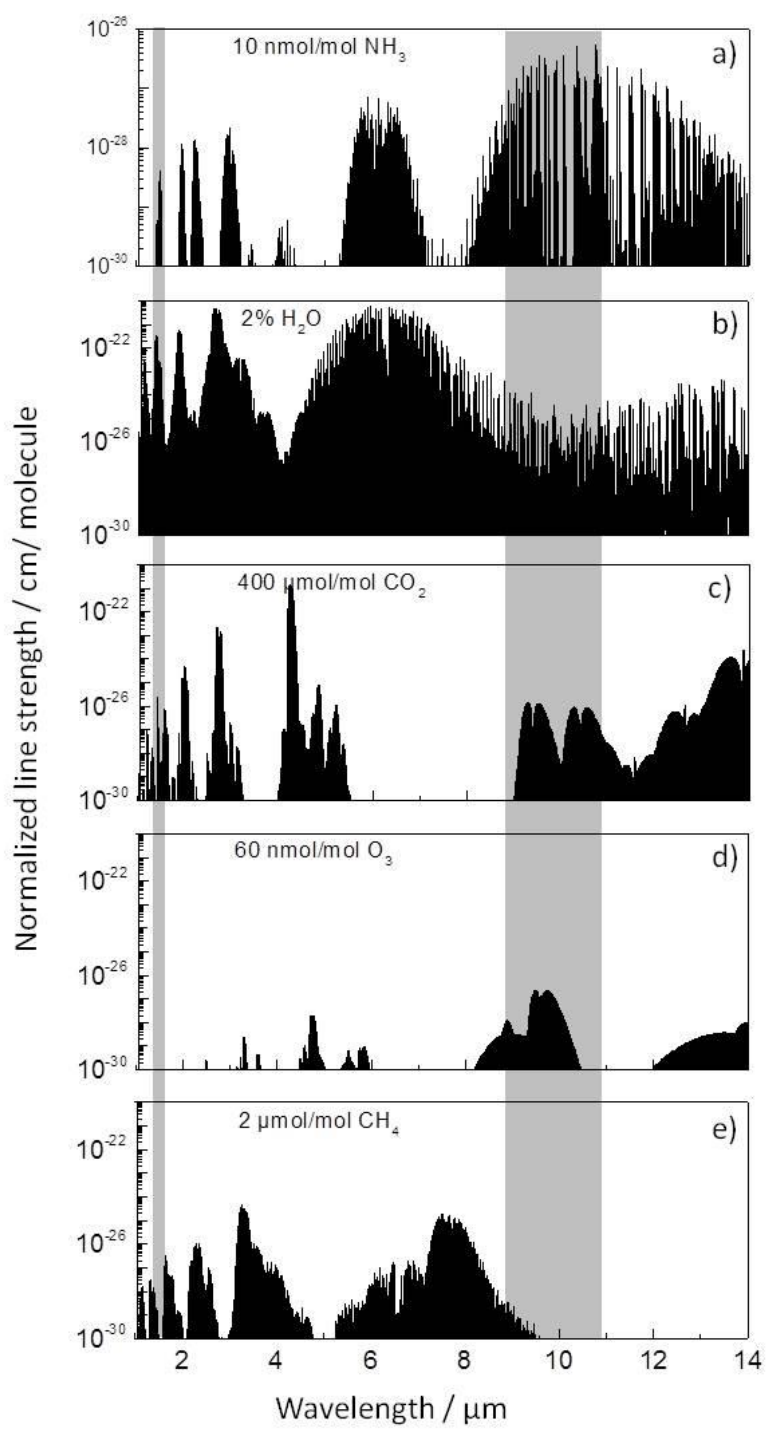

Figure 2: Simulated infrared spectrum of a) ammonia and common atmospheric interferers: b) water vapour, c) carbon dioxide, d) ozone and e) methane. The wavelength ranges commonly used for ammonia measurements are marked with grey shading. Normalized line strength refers to the line strengths multiplied by typical ambient concentrations (see legend). Data are taken from the HITRAN 2012 database [25]. 
Two wavelength ranges (indicated by grey shading in Figure 2) are frequently used for ambient ammonia

230 analysis by spectroscopy, both having their advantages and disadvantages. The wavelength range around 1.51-

$231 \quad 1.54 \mu \mathrm{m}\left(6500-6600 \mathrm{~cm}^{-1}\right)$ has been accessible over a decade using inexpensive, robust diode lasers produced

232 for dense wavelength division multiplexing (DWDM) in the telecommunication industry. However, the rather

233 small line strength of the ammonia lines in this range $\left(<2 \times 10^{-21} \mathrm{~cm} / \mathrm{molecule}\right)$ requires the use of extremely

234 sensitive detection techniques. On the other hand, measurements using the strongest ammonia absorption

235 lines in the mid-infrared (MIR) range around 9-11 $\mu \mathrm{m}\left(900-1100 \mathrm{~cm}^{-1}\right)$ were, and to a certain extent still are,

236 hindered by the limited availability of light sources, detectors and optical components for this wavelength

237 range. Earlier, mainly line tuneable carbon dioxide lasers and lead salt diodes requiring cryogenic cooling were

238 used in this wavelength range [26], while the rapid development of room temperature quantum cascade lasers

239 makes measurements in this wavelength range much more feasible nowadays [27].

240 Besides spectroscopic aspects, another crucial part is the gas sampling system of the spectrometer.

241 Extractive spectrometers are susceptible to bias and long response times caused by adsorption-desorption

242 processes in the inlet line, and/or in the measurement cell itself. An open path or a sampling-free spectrometer

243 does not suffer from such adsorption problems and has the potential to provide significantly shorter response

244 times [27][28].

245 The MetNH3 project investigates two types of spectrometers, one operating in each of afore mentioned 246 wavelength ranges. Commercial cavity ring-down spectrometers (Model G2103, Picarro Inc.) are being used by 247 several project partners and are being characterized from a metrological point of view. These spectrometers 248 use extractive sampling method, i.e., a gas sample is flown continuously through the measurement cell with $249 \sim 1 \mathrm{slm}$ (standard litre per minute) flow rate. Spectroscopic detection is performed around $6548 \mathrm{~cm}^{-1} \mathrm{using}$ a 250 diode laser light source. Besides, a sampling-free spectrometer is being developed and characterized in the 251 project. This spectrometer is based on an open multi-pass cell, where ambient air flows freely between the two 252 mirrors, and uses a quantum cascade laser light source operating around $1103.5 \mathrm{~cm}^{-1}$.

253 To overcome the problem of limited accuracy and availability of calibration standards (as described in 254 Sections 2.1. and 2.2.), many spectrometers target absolute amount fraction measurements based on the Beer255 Lambert law [27][29][30][31], however, only a few of them are thoroughly characterized and validated from a 256 metrological point of view [31]. Our recent studies show that absolute spectroscopic measurement techniques 257 (direct tuneable diode laser absorption spectroscopy (dTDLAS) [30][31], quantum cascade laser absorption 258 spectroscopy (QCLAS) or cavity ring-down spectroscopy (CRDS)) have the potential to achieve traceability in 259 spectroscopic amount fraction measurements without the need for regular calibration with gas standards. (Of 260 course, validation, e.g., against a well characterized, traceable reference gas mixture is still necessary [31].) 261 Absolute determination of the ammonia amount fraction $\left(x_{\mathrm{NH}_{3}}\right)$ is based on the Beer-Lambert law according to 262 the following equation:

$$
x_{N H_{3}}=\frac{T \cdot \alpha_{\text {int }} \cdot k_{B}}{S_{T} \cdot p \cdot r_{i s o}}
$$

for CRDS and 


$$
x_{N H_{3}}=\frac{T \cdot A_{\text {int }} \cdot k_{B}}{S_{T} \cdot L \cdot p \cdot r_{i s o}}
$$

for dTDLAS and QCLAS. Traceability of the input parameters pressure $(p)$ and temperature $(T)$ of the gas sample and optical path length of the cell $(L)$ have already been achieved [30]. The Boltzmann-constant $\left(k_{\mathrm{B}}\right)$ is known with very high accuracy. The isotopic ratio (represented by the correction factor $r_{\text {iso }}$ ) of gas samples originating from natural sources can be estimated with sufficient accuracy based on natural abundances [32]. Usually the line intensity of the probed transition $\left(S_{T}\right)$ and the integrated absorption coefficient $\left(\alpha_{\text {int }}\right)$ or integrated absorbance $\left(A_{\text {int }}\right)$ are the most challenging parameters.

The quality of available spectral line data in literature is often not satisfactory, and frequently the limiting factor in absolute spectroscopic amount fraction measurements. As an example, until 2012 the HITRAN database [25], the most frequently used spectroscopic database in atmospheric science, did not contain any data of ammonia for wavelengths below $2 \mu \mathrm{m}$, and even in the latest edition of the database, uncertainties of the ammonia absorption line intensities are typically as high as 5-20\%. More detailed studies of individual, application-specifically selected absorption lines (e.g. in [33]) provide only slightly lower uncertainties for a very limited number of absorption lines. There is a clear need for more accurate and traceable spectral line data. This problem will be addressed in the MetNH3 project. A recent project showed that traceable measurement of spectral line data of different analytes can be achieved, providing also considerably lower uncertainties than currently existing spectral databases [34]. Recently, a robust and flexible method has been developed to achieve traceable line intensities using tuneable diode laser absorption spectroscopy. The measurements are performed in pure gases to reduce uncertainty in the analyte amount fraction, and at low pressures (below $10 \mathrm{hPa}$ ) to decrease pressure broadening and ensure good separation of the absorption lines. Distributed feedback diode laser(s) are used as light source to provide high spectral resolution, combined with a single-pass gas cell to decrease alignment errors and provide the opportunity to perform measurements within a large wavelength range using the same set-up (limited only by the transmissivity of the cell windows). Applicability of the method for the measurement of $\mathrm{CO}_{2}$ and $\mathrm{H}_{2} \mathrm{O}$ line intensities with expanded uncertainties in the 1-3\% range has already been demonstrated [35][36]. A similar method will be applied to measure line intensities of the probed ammonia transitions. Similarly, pressure broadening coefficients have been measured [37] using a method which can also be applied for ammonia. It is also aimed to achieve traceability of the integrated absorption coefficient $\left(\alpha_{\text {int }}\right)$ or integrated absorbance $\left(A_{\text {int }}\right)$. To achieve traceability and quantify uncertainties, a spectral fitting algorithm is being developed within the project. Details of this algorithm are given in Section 3.2 .

Based on such absolute, traceable spectroscopic techniques an optical transfer standard can be developed. Instead of regular calibration using gas standards, the individual components of the spectrometer, i.e., which give the input parameters of equation (1) and (2), have to be calibrated regularly against traceable references. This is in most cases (e.g. the calibration of pressure and temperature sensors) easier, provides longer stability and can be performed with higher accuracy than calibration of a complete spectrometer using gas standards. We note that validation using traceable reference gas mixtures is still necessary to ensure that no unrevealed sources of bias are present, but is not required as often as calibration in the case of non-absolute measurement 
methods. Furthermore, validation of an absolute analytical instrument with a traceable reference gas

304 generator provides more confidence in the reliability of both devices.

305 An optical transfer standard offers therefore a third alternative besides gas cylinders with appropriate 306 dilution systems and dynamic reference gas generators to calibrate or validate field instrumentation. Similarly 307 to mobile reference gas generators, an optical transfer standard serves as an ideal transfer standard for 308 extensive measurement networks, where calibrations with the same standard are preferred. Additionally, if gas 309 mixture generators are not available, an optical transfer standard can be used for calibration with any kind of 310 gas mixture (even ambient air); the reference ammonia amount fraction is provided by the optical transfer 311 standard.

\section{2.4. Test facilities for inter-comparison measurements}

313 To offer a suitable infrastructure for the validation and comparison experiments, two test facilities are 314 being developed in the MetNH3 project. These facilities enable the distribution of gas mixtures provided from 315 gas cylinders or dynamic generators (or even ambient air) to several ammonia monitoring devices (passive or 316 active samplers or analytical instruments) without changing its composition, as schematically shown in 317 Figure 3 . Such test facilities are not necessarily compicated and bulky installations; e.g., in case only a few 318 devices are to be compared, the test facility can be a very simple gas manifold made of a few tubes and fittings. 319 Nevertheless, in this section we describe two test facilities, which are being developed within the MetNH3 320 project and are designed for larger scale inter-comparison measurements involving different types of gas 321 standards and analytical instruments.

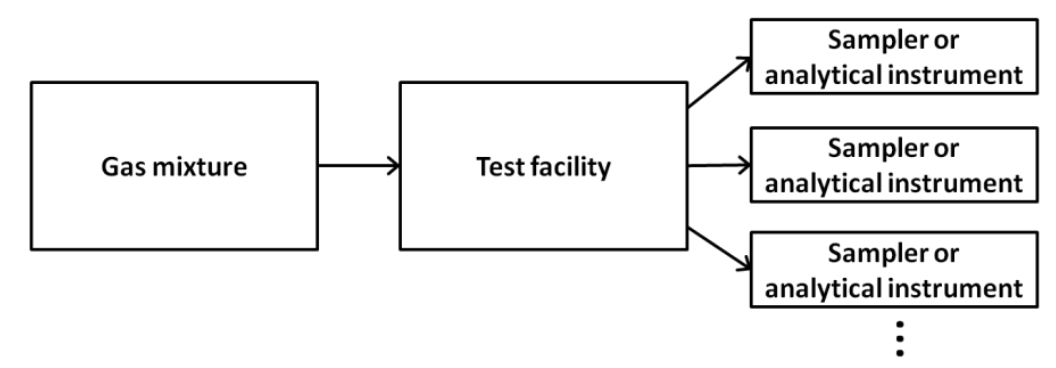

Figure 3: Schematics of an experimental set-up for validation experiments

The first facility, the Controlled Atmosphere Test Facility (CATFAC) is an aerodynamic wind tunnel 326 ammonia concentration, relative humidity, air temperature and air speed. Test atmospheres are generated by

327 dynamically blending stable ammonia reference gas mixtures from cylinders with purified air using calibrated 328 mass flow controllers. The test gas is continuously re-circulated and replenished in the facility by a freshly 329 generated mixture of the same composition. The total replenishment flow rate is up to 30 slm. Stabilization 330 time of the ammonia amount fraction in the chamber depends strongly on the composition of the gas mixture, 331 and is typically in the range of a few hours. The specified conditions can easily be maintained over time 332 intervals of a few hours to several weeks. The CATFAC is primarily designed for carrying out exposure tests with 333 smaller devices, e.g., different types of ammonia samplers, which are placed inside the facility. Additionally, 334 larger devices, e.g., active denuders or extractive spectrometers, can be connected to the facility to sample the 
336 [39] have already been performed and showed good results. The agreement between calculated and measured ammonia amount fractions was better than $3 \%$ at the $40 \mathrm{nmol} / \mathrm{mol}$ level. A photograph of the CATFAC, without its insulation, is shown in Figure 4.
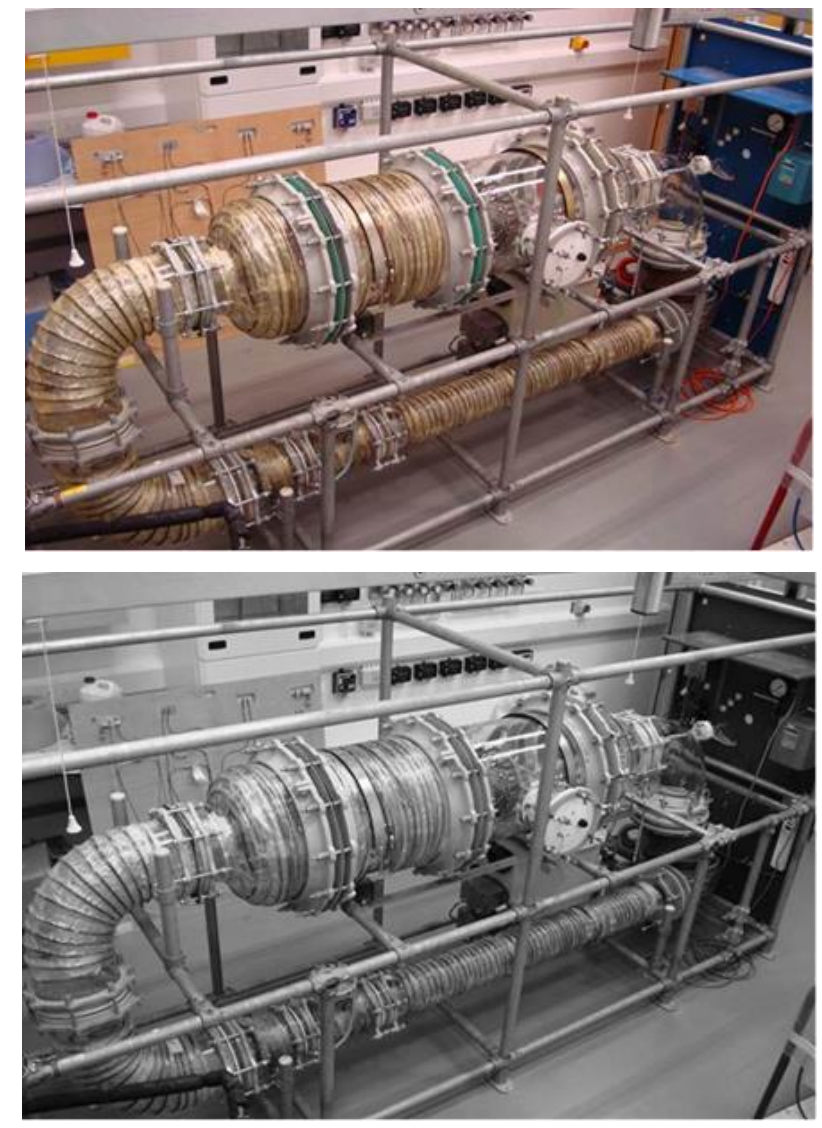

Figure 4: Photograph of the Controlled Atmosphere Test Facility (CATFAC) (colour online)

The second facility is a proficiency test facility, developed for the characterization of the performance of extractive analytical instruments. The facility has been used for comparison experiments for common air pollutants like $\mathrm{NO}, \mathrm{NO}_{2}, \mathrm{SO}_{2}, \mathrm{CO}$ and $\mathrm{O}_{3}$ [40], and is currently being adapted for experiments with $\mathrm{NH}_{3}$ mixtures under dry and humid conditions. The facility consists of a glass line with multiple sampling ports for the individual instruments. The installation operates under ambient temperature and pressure. Complex gas mixtures can be added to the gas line from up to 14 pressurized gas cylinders and a dilution system using mass flow controllers. Time-programmed step changes in the concentration of the individual mixtures can be applied, controlled by an industrial computer. Gas mixtures from cylinders prepared within the MetNH3 project, as well as dynamic generators will be fed into the facility. In addition, an ambient air line can be used

353 to provide air from outside the building to the connected instruments. The proficiency test facility will be used

354 to test newly developed instruments with respect to potential interference gases, and to select the most 355 suitable transfer standard for ambient measurements. 
Due to the highly adsorptive nature and reactivity of ammonia, adsorption-desorption processes on different material surfaces crucially influence both the preparation of reference materials and the design of analytical instruments. Adsorption induces a negative, while desorption a positive bias in the measured ammonia amount fraction. Adsorption and desorption are opposite and largely reversible processes [43]. Consequently, the results of studies investigating the adsorption on different surfaces can be taken as a good estimate for desorption as well. The extent of adsorption of ammonia on glass, metal and polymer surfaces is known to be significantly different [41][42][43], which makes the choice of the gas wetted materials a central question in designing gas handling systems. Metal surfaces adsorb a large amount of ammonia, which can be decreased by about $50 \%$ by electro-polishing the surface. A more significant reduction of adsorption can be achieved by adding an inert coating (e.g. SilcoNert 2000, trademark of SilcoTek Corporation [44]) on stainless steel, and polymer surfaces adsorb even less ammonia than coated metal surfaces. An example for the extent of ammonia adsorption on different material surfaces is given in Table 1 and Ref.[41].

Table 1. Adsorption of ammonia on some surface materials. The measurement conditions were the following: ammonia amount fraction $425 \mathrm{nmol} / \mathrm{mol}$, gas flow rate $1000 \mathrm{~cm}^{3} / \mathrm{min}$, pressure $176 \mathrm{hPa}$ and temperature $295 \mathrm{~K}$ (part of the data taken from [41]).

\begin{tabular}{|c|c|c|}
\hline Surface material & $\begin{array}{l}\text { Adsorption of ammonia } \\
/ 10^{12} \text { molecule } \cdot \mathrm{cm}^{-2}\end{array}$ & $\begin{array}{l}\text { Standard deviation (of } 3 \text { measurements) } \\
/ 10^{12} \text { molecule } \cdot \mathrm{cm}^{-2}\end{array}$ \\
\hline Stainless steel $316 \mathrm{~L}$ & 138 & 21 \\
\hline Electropolished stainless steel $316 \mathrm{~L}$ & 72 & 11 \\
\hline Dursan (SilcoTek Corp.) & 101 & 5 \\
\hline SilcoNert 1000 (SilcoTek Corp.) & 15 & 1 \\
\hline SilcoNert 2000 (SilcoTek Corp.) & 6 & 1 \\
\hline $\begin{array}{l}\text { Teflon-perfluoroalkoxy (Teflon- } \\
\text { PFA) }\end{array}$ & 4 & $\mathrm{n} / \mathrm{a}$ \\
\hline
\end{tabular}

The preferred materials for the inlet lines of analyzers are polymers including Teflon (PTFE), Teflonperfluoroalkoxy (Teflon-PFA) or polyvinylidene fluoride (PVDF). Gas cells, valves and flow control units, where better mechanical stability is required, are often made of coated stainless steel or pyrex. Similarly, most cylinder manufacturers apply internal passivation treatments or coatings on aluminium cylinders to reduce adsorption losses. Studies into using an "active passivation method" by entraining functionalized perfluoroalkane vapour into the inlet sampling stream are also currently under way to reduce the adsorption effects in spectroscopic analyzers; these are, however, still in the research phase [45]. Sampling-free analytical instruments are most preferred to overcome artefacts caused by adsorption-desorption processes.

Humidity of the gas sample has a strong effect on the adsorption processes; however, the nature of this

382 dependence still leaves open questions. For instance, the effect of humidity on ammonia adsorption, driven by 383 the competitive adsorption between ammonia and water, is unclear. Vaittinen et al. [41] observed that 
increased water vapour concentration causes a remarkable decrease in adsorption losses of ammonia, while experiments performed by Ellis et al. [46] show the opposite. We note that this inconsistency can be explained by different definitions of "dry samples" in the two publications. It has been observed that ammonia adsorption in gas samples with water vapour amount fraction below $100 \mu \mathrm{mol} / \mathrm{mol}$ is up to a factor of 5 higher than in the case of slightly elevated water vapour amount fractions (up to a few $1000 \mu \mathrm{mol} / \mathrm{mol}$ ). At humidity levels $>10000 \mu \mathrm{mol} / \mathrm{mol}$, ammonia losses in the sampling system increase again. This non-monotonic dependence of ammonia adsorption on humidity results in fundamentally different observations in experiments performed in slightly different humidity ranges.

Elevated temperatures are known to decrease adsorption, thus heating the sampling lines or the measurement cell is a common method to prevent condensation and further decrease adsorption losses. However, in the case of ambient air measurements, there are concerns that elevated temperature leads to a partitioning of aerosol, such as $\mathrm{NH}_{4} \mathrm{NO}_{3}$, into $\mathrm{NH}_{3}$ and $\mathrm{HNO}_{3}$ in the gas phase, leading to a positive bias in the measurements [11]. The use of filters and impactors to remove aerosols from the air stream prior to entering the heated sampling line is a widespread method to reduce this positive bias, as well as to prevent contamination of the measurement cell. In this case it is important that filters are changed regularly to prevent reaction of gas phase ammonia with the aerosol phase captured on the filter, or volatilization of the captured aerosols.

\section{Results}

This section presents results obtained during the first year of the MetNH3 project in two fields. In Section 3.1 we present results of adsorption studies in gas cylinders and in gas handling lines made of different materials, and with different coatings. Section 3.2 describes first results obtained in the spectroscopic detection of ammonia with the Picarro G2103 spectrometer.

\subsection{Study of adsorption losses in static and dynamic set-ups}

Adsorption of ammonia in material surfaces is an important issue in several parts of the measurement system. In this chapter two examples are presented: 1 ) adsorption on the walls of gas cylinders after different cylinder passivation treatments, which determines uncertainty in the prepared static gas mixtures and 2) adsorption in gas handling tubes made of different materials, which influences accuracy of dynamic systems.

An initial screening of a range of commercially available passivated gas cylinders was carried out by gravimetrically preparing a number of mixtures of ammonia in nitrogen at 100 and $10 \mu \mathrm{mol} / \mathrm{mol}$. Two mixtures were prepared per amount fraction per cylinder type, which were then analysed on a non-dispersive infrared (NDIR) spectrometer or on a photoacoustic spectrometer (PAS). These measurements allowed the determination of the ammonia response factor for each mixture based on the instrument response and on the gravimetric amount fraction. The ammonia response factor for a mixture prepared in a cylinder that suffers from adsorption effects is lower than that of a mixture prepared in a cylinder in which adsorption occurs to a smaller extent: these measurements therefore allowed filtering out unsuitable cylinders that showed evident ammonia adsorption. The two analytical techniques have comparable uncertainties and were only used for 
relative measurements (comparison of response factors of cylinders), which ensures comparability of the 421 results obtained by either method.

$422 \quad$ Three cylinder types showed promising results and were subjected to further tests. These included two 423 types of passivated aluminium cylinders, which are frequently used for commercial ammonia mixtures (Spectra 424 Seal $^{\mathrm{TM}}$; treatment trademark of BOC [47] with $10 \mathrm{I}$ internal volume and Aculife ${ }^{\mathrm{TM}}$ treatment trademark of Air 425 Liquide [48] with $5 \mathrm{I}$ internal volume, both filled up to 140 bar). Aculife is the family name of a series of 426 proprietary cylinder treatments that is utilized to enhance the stability of reactive gas mixtures. We note that 427 Airliquide has developed different types of Aculife cylinder treatments that are adopted for different 428 components and concentration ranges; in particular, the treatment used in this study was the one 429 recommended for ammonia mixtures at the time of measurement, but a more suitable one has since become 430 available. The third cylinder type was a commercially available stainless steel cylinder with internal surfaces 431 coated with SilcoNert2000 [44] with 3.785 I internal volume and filled up to 120 bar pressure.

These three cylinder types underwent a series of decanting tests in order to quantify the extent of 433 ammonia surface adsorption. For each cylinder type, two mixtures were prepared at $100 \mu \mathrm{mol} / \mathrm{mol}$ and two at $43410 \mu \mathrm{mol} / \mathrm{mol}$ (except for the SilcoNert2000 cylinders, which were only tested at $10 \mu \mathrm{mol} / \mathrm{mol}$ ); these were 435 certified against a dynamic dilution of ammonia mixtures at higher amount fractions using NDIR or PAS prior to 436 decanting. Each parent mixture was then decanted into an evacuated daughter cylinder of the same type; and 437 following the decanting, all parent and daughter mixtures were certified against the dynamic system.

438 The results of the decant tests are shown in Tables 2 and 3. In Table 2, direct comparison of the certified 439 ammonia amount fractions of the parent mixtures pre-decant and those of the corresponding daughter 440 mixtures provides a measure of the amount of ammonia adsorbed on the cylinder walls. Losses of $441 \sim 0.5 \mu \mathrm{mol} / \mathrm{mol}$ on average are observed for Spectra Seal and Aculife cylinders, whereas the same tests 442 performed on SilcoNert2000-treated cylinders showed indiscernible losses $(<0.1 \mu \mathrm{mol} / \mathrm{mol})$. The attribution of 443 the ammonia losses observed in Spectra Seal and Aculife cylinders to the transfer line used for the decant at $44410 \mu \mathrm{mol} / \mathrm{mol}$ can be ruled out, as the same line was used for all cylinder types. In the light of the analytical 445 uncertainty of the measurements (approximately $1 \%$ at the $k=2$ level for both amount fractions), the 446 observed losses are only significant at the $10 \mu \mathrm{mol} / \mathrm{mol}$ level for Spectra Seal and Aculife cylinders. Therefore, 447 at $10 \mu \mathrm{mol} / \mathrm{mol}$, adsorption of ammonia molecules on cylinder walls is minimised when the internal surfaces of 448 stainless steel cylinders are passivated using SilcoNert2000. In Table 3, direct comparison of the certified 449 amount fraction of each parent mixture pre- and post-decant allows the detection of any effects arising from a $45050 \%$ pressure drop: these are often observed in cylinders where adsorption of reactive or polar species to the 451 internal walls occurs, as molecules start to desorb from the walls as the pressure is lowered. The observed 452 variations in the ammonia amount fraction were found to be smaller than the analytical uncertainty of the 453 measurements in all cases.

454 Stainless steel cylinders with SilcoNert2000 internal coating showed the least adsorption for $\mathrm{NH}_{3}$. However, 455 Spectra Seal and Aculife cylinders have a larger internal volume, can be filled to higher pressures and are 456 cheaper to produce, therefore these would be better suited for field calibration work once they have been 457 accurately certified against standards, e.g., in SilcoNert2000 coated cylinders. 
Table 2: Difference in certified ammonia amount fraction between parent mixtures pre-decant and daughter 459 mixtures

\begin{tabular}{|c|c|c|c|}
\hline \multicolumn{4}{|c|}{$\mathrm{NH}_{3}$ amount fraction change $(\mu \mathrm{mol} / \mathrm{mol})$} \\
\hline & Spectra Seal $^{\mathrm{a}}$ & Aculife $^{b}$ & $\begin{array}{c}\text { SilcoNert2000 } \\
\mathrm{a}\end{array}$ \\
\hline $\begin{array}{c}100 \mu \mathrm{mol} / \mathrm{mol} \\
\text { mixtures }\end{array}$ & $\begin{array}{l}-0.50 \pm 1.0 \\
-0.54 \pm 1.0\end{array}$ & $\begin{array}{l}-0.86 \pm 1.0 \\
-0.28 \pm 1.0\end{array}$ & - \\
\hline $\begin{array}{c}10 \mu \mathrm{mol} / \mathrm{mol} \\
\text { mixtures }\end{array}$ & $\begin{array}{l}-0.70 \pm 0.10 \\
-0.14 \pm 0.10\end{array}$ & $\begin{array}{l}-0.49 \pm 0.10 \\
-0.67 \pm 0.10\end{array}$ & $\begin{array}{l}-0.02 \pm 0.10 \\
+0.07 \pm 0.10\end{array}$ \\
\hline
\end{tabular}

461 Table 3: Difference in certified ammonia amount fraction of the parent mixtures pre- and post-decant

$\mathrm{NH}_{3}$ amount fraction change $(\mu \mathrm{mol} / \mathrm{mol})$

\begin{tabular}{|c|c|c|c|}
\hline & Spectra Seal $^{\mathrm{a}}$ & Aculife $^{\mathrm{b}}$ & $\begin{array}{c}\text { SilcoNert2000 } \\
\mathrm{a}\end{array}$ \\
\hline $\begin{array}{c}100 \mu \mathrm{mol} / \mathrm{mol} \\
\mathbf{m i x t u r e s}\end{array}$ & $+0.09 \pm 1.00$ & $+0.25 \pm 1.00$ & - \\
\hline $\begin{array}{c}10 \mu \mathrm{mol} / \mathrm{mol} \\
\text { mixtures }\end{array}$ & $-0.17 \pm 1.00$ & $+0.53 \pm 1.00$ & - \\
\hline \multicolumn{2}{|c|}{$-0.06 \pm 0.10$} & $-0.02 \pm 0.10$ & $+0.06 \pm 0.10$ \\
\hline analyzed by NDIR, ${ }^{\mathrm{a}}$ analyzed by PAS & $+0.06 \pm 0.10$ & $0.00 \pm 0.10$ \\
\hline
\end{tabular}

In dynamic measurements, four different types of tubing have been tested in our experiments:Teflon PFA, uncoated electro-polished stainless steel, and electro-polished stainless steel with SilcoNert2000 coating (SilcoTek Ltd. [44]) and Supelco coating (Sigma Aldrich). Some of these materials were also included in the study by Vaittinen et al. [41]. As described in the caption of Table 1, the experiments of Vaittinen et al. [41] were performed at $176 \mathrm{hPa}$ pressure. Although the amount of adsorbed molecules is not expected to show significant pressure dependence in this pressure regime, we found it reasonable to repeat the measurements at atmospheric pressure, which better represents the conditions of sampling inlets of analytical instrumentation, as well as gas handling lines in dynamic generators. Besides, the typically high uncertainties (standard deviation in Table 1 in the range of 5 to $15 \%$ ) observed in adsorption measurements justify repetition of the experiments to gain more confidence in the results.

The experiments followed the procedure published by Vaittinen et al. [41]. The measurement system consisted of a gas generator applying the permeation method described in Section 2.2, which was connected to 475 a CRDS analyser (Picarro G 2103). This set-up was continuously purged with a mixture of $330 \mathrm{nmol} / \mathrm{mol} \mathrm{NH}_{3}$ in 
$N_{2}$ 5.0. Alternatively, the gas stream can be directed to a test tube before reaching the analyzer, via two SilcoNert2000 coated manually-operated 3-way valves. Prior to exposure to the $\mathrm{NH}_{3}$ mixture, the test tube was flushed for 60 minutes with ambient air to remove residual adsorbed $\mathrm{NH}_{3}$, which process is facilitated by the humidity. The adsorbed water is thereafter removed by flushing the test tube for 30 minutes with $\mathrm{N}_{2} 5.0$ with water vapour content below $500 \mathrm{nmol} / \mathrm{mol}$. The test tube was then exposed to the $\mathrm{NH}_{3}$ mixture. Adsorption on the surface of the test tube causes a sudden drop of $\mathrm{NH}_{3}$ measured concentrations, as shown in Figure 5 , whereafter $\mathrm{NH}_{3}$ concentrations slowly recover; the timing of the recovery strongly depending on the material surface. The amount of adsorbed molecules is determined from the area of the observed dip in the measured $\mathrm{NH}_{3}$ amount fractions. The numbers of adsorbed $\mathrm{NH}_{3}$ molecules per unit surface area have been determined until $\mathrm{NH}_{3}$ amount fractions have recovered to $99 \%$ of the initial values. The mean values and the relative standard deviations over 3 measurements of the different materials are as follows: PFA:

$(23.9 \pm 7.1) \cdot 10^{12}$ molecules $/ \mathrm{cm}^{2}$, Stainless Steel electro-polished: $(152.8 \pm 6.5) \cdot 10^{12} \mathrm{molecules} / \mathrm{cm}^{2}$. The experiments have been carried out at a flow rate of $1500 \mathrm{~cm}^{3} / \mathrm{min}$, ambient pressure and $293 \mathrm{~K}$ temperature. Adsorption in pristine test tubes not previously exposed to ammonia might be higher than the numbers presented here. However, our repeated measurements show that after the first exposure the amount of adsorbed molecules is reproducible within the experimental uncertainty during each subsequent exposure.

The measured numbers of adsorbed molecules per unit surface area were in the same order of magnitude as the results presented in Table 1 in Section 2.5 and confirmed the same relations between the three materials, which were included in both studies (Teflon-PFA, SilcoNert2000, stainless steel). We note that the differences of the results of this study from previous results shown in Table 1 are not significant and are most probably caused by different amount of residual humidity in the used gas mixtures. Teflon-PFA and SilcoNert 2000 coated stainless steel proved to be the best suited materials to reduce adsorption. Despite of the slightly higher adsorption, SilcoNert 2000 coated stainless steel tubing was found to be a better choice than

500 Teflon-PFA polymer tubing, due to its higher mechanical stability and lower porosity and diffusion.

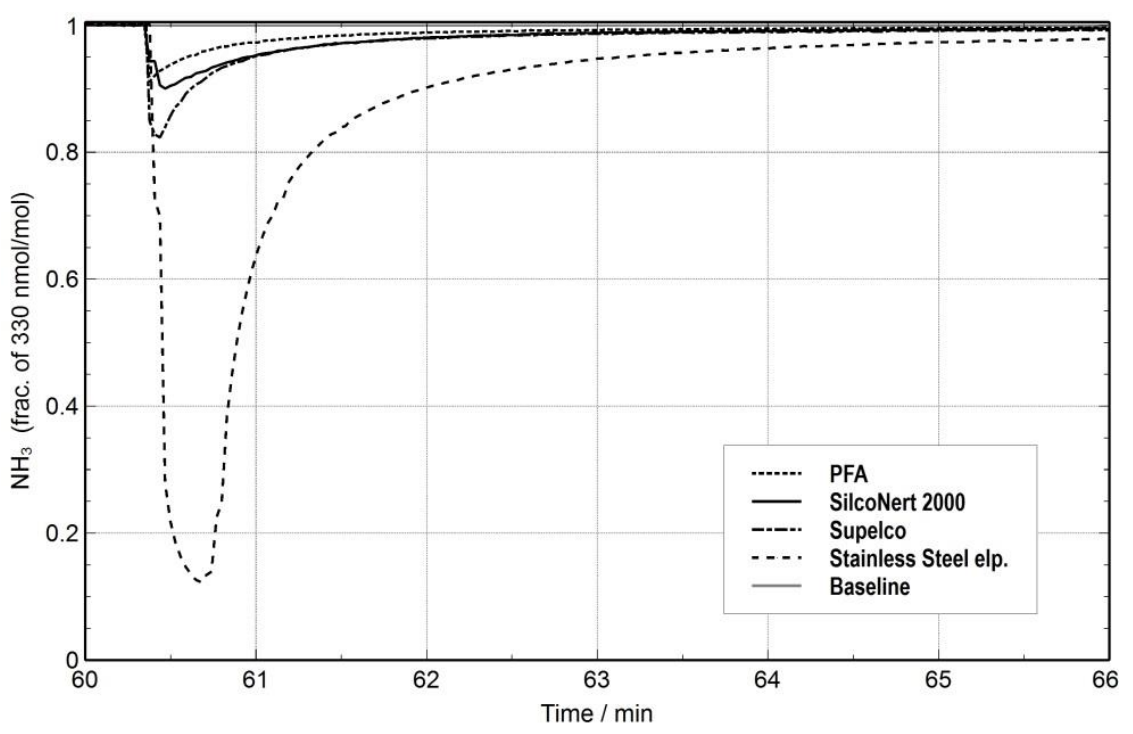

Figure 5: Ammonia gas phase concentration as a function of time in an experiment where clean test tubes of 
504 adsorption and gas exchange occurring in the tube. The results displayed are the averages over 3 identical 505 experiments.

\section{3.2. Towards traceability in the spectroscopic detection of ambient ammonia} addressed by the development of a novel data evaluation algorithm, which takes into account all revealed sources of bias. Special emphasis is put on determining uncertainties in the individual input parameters, aiming to give a reliable uncertainty figure for the final ammonia amount fraction as well.

Figure 6 shows a typical spectrum measured by the Picarro spectrometer in a gas mixture of $100 \mathrm{nmol} / \mathrm{mol}$ $\mathrm{NH}_{3}$ and $2 \% \mathrm{H}_{2} \mathrm{O}$ in nitrogen. The black symbols indicate the 36 wavenumbers within a spectral window of $0.7 \mathrm{~cm}^{-1}$, where ring-down time measurements are carried out by the spectrometer. The number of measurement points is limited by the free spectral range of the cavity and cannot be increased without significant technical efforts to vary the cavity length during the measurement.

The internal evaluation algorithm of the spectrometer uses a complex spectral fitting algorithm to determine the peak height of the ammonia absorption lines. Ammonia amount fraction is calculated from the obtained peak heights. Similarly, heights of the water vapour peaks are determined and used for the calculation of water vapour amount fractions, which is necessary for the correction of cross-sensitivities originating from the overlapping absorption lines. We note that details of the fitting and data evaluation algorithm are (as in case of most commercial instruments) not fully revealed to the spectrometer user. To verify correctness of this data evaluation algorithm, an own algorithm is being developed within the MetNH3 project to process the raw spectra. This involves a multi-line fitting algorithm based on our previous works [49][50], where ammonia amount fraction is calculated from the integrated absorption coefficient $\left(\alpha_{\text {int }}\right)$ of the ammonia lines using the Beer-Lambert law (equation (2)). The fitting algorithm takes into account six $\mathrm{NH}_{3}$ lines, eight $\mathrm{H}_{2} \mathrm{O}$ lines and two $\mathrm{CO}_{2}$ lines, which have influence on the spectrum measured in this spectral window. Other common atmospheric components, e.g., $\mathrm{CH}_{4}$ or $\mathrm{O}_{3}$ have no measurable absorption lines in this wavelength range and are therefore not included in the fitting algorithm. Even the spectral influence of the $\mathrm{CO}_{2}$ lines has been found to be minor (less than $5 \cdot 10^{-6}$ relative change in the measured $\mathrm{NH}_{3}$ amount fraction per $\mu \mathrm{mol} / \mathrm{mol}$ change in the absolute $\mathrm{CO}_{2}$ amount fraction). Figure $6 \mathrm{a}$ and $\mathrm{b}$ show the fitted lines and residuals in a gas mixture containing $100 \mathrm{nmol} / \mathrm{mol} \mathrm{NH}_{3}$ and $2 \% \mathrm{H}_{2} \mathrm{O}$.

The uncertainty in the integrated absorption coefficient $\left(\alpha_{\text {int }}\right)$ has been found to be in the $0.5-9 \%$ range, depending on the $\mathrm{NH}_{3}$ and $\mathrm{H}_{2} \mathrm{O}$ amount fractions. This uncertainty is dominated by three main effects: 1) the uncertainty in the measured ring-down times, 2) the limited number of measurement wavenumbers across the absorption lines and 3) the complexity of the measured absorption spectra. Besides, uncertainty of the line intensity $\left(S_{T}\right)$ is significant. Currently we use literature values, which have an absolute accuracy of $10 \%$. However, line intensity measurements, which will reduce the expanded uncertainty of $S_{0}$ below $3 \%(k=2)$ are in progress, and first results are presented in [51]. The uncertainty contributions of the pressure, temperature and isotopic composition of the gas sample are negligible, provided that the sensors are regularly calibrated against a traceable reference and samples with natural isotopic composition are measured. 

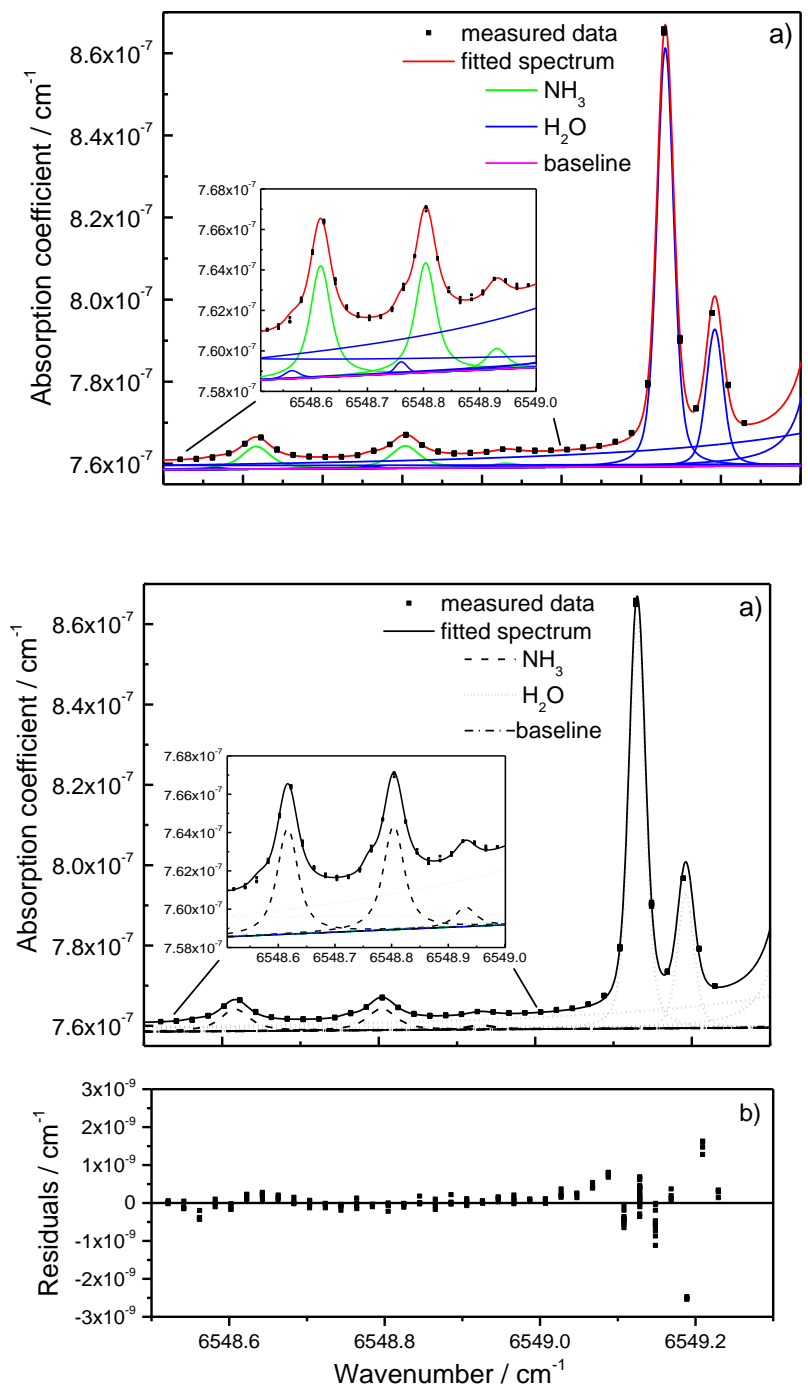

Figure 6: Measured raw data points with the fitted spectrum (a) and residuals (b) in $100 \mathrm{nmol} / \mathrm{mol} \mathrm{NH}_{3}$ and $2 \%$ $\mathrm{H}_{2} \mathrm{O}$ in $\mathrm{N}_{2}$. The measurements were performed using a Picarro G2103 spectrometer. (colour online)

Two phenomena have been observed so far, where a newly developed data evaluation algorithm might excel over the data evaluation algorithm provided by the spectrometer manufacturer. As shown in Figure 6, the probed $\mathrm{NH}_{3}$ absorption lines strongly overlap with $\mathrm{H}_{2} \mathrm{O}$ absorption lines. Spectral interference is expected due to two reasons: a) direct spectral overlap of absorption lines and b) change in the width of the $\mathrm{NH}_{3}$ absorption lines due to varying $\mathrm{H}_{2} \mathrm{O}$ concentration in the matrix gas [52]. The cross-sensitivity is supposed to be corrected by the data evaluation algorithm of the spectrometer; however, we observed up to a few percent differences between the readings in dry and humid gas samples. Figure 7a shows two calibration lines obtained for the

554 CRDS instrument: one in dry gas samples and one in humidified samples with relative humidity of $70 \%$ at $20{ }^{\circ} \mathrm{C}$

555 (corresponding to $\sim 1.65 \%$ absolute $\mathrm{H}_{2} \mathrm{O}$ amount fraction, the samples were prepared in the CATFAC facility; see Section 2.4 for more details). The slope of the two calibration lines differ by $\sim 4 \%$, which indicates crosssensitivity to $\mathrm{H}_{2} \mathrm{O}$. The data evaluation algorithm is currently being further developed to account for this crosssensitivity [53]. 
It has also been observed that the measured ammonia amount fractions are influenced by the composition of the matrix gas. Figure $7 \mathrm{~b}$ illustrates this effect through measurements in air and nitrogen matrix gases in the $50-200 \mathrm{nmol} / \mathrm{mol} \mathrm{NH}_{3}$ amount fraction range. Instrument response refers to the ratio of the measured and reference ammonia amount fractions, and has been normalized to the average of the measurements in air, to show relative changes caused by changing the matrix gas. Error bars in the Figure represent estimated expanded uncertainty of the measurements, dominated by uncertainty of the ammonia amount fraction in the reference gas (prepared by dynamic dilution from a commercial gas mixture of $10 \mu \mathrm{mol} / \mathrm{mol} \mathrm{NH}_{3}$ in $\mathrm{N}_{2}$ ). As it can be seen in Figure $7 \mathrm{~b}$, the data evaluation algorithm provided by the manufacturer results in $\sim 10 \%$ lower readings in nitrogen matrix gas, compared to air. The data evaluation algorithm developed within the MetNH3 project gives normalized instrument response close to one in both air and nitrogen matrix gases. The reason for this difference is that the manufacturer algorithm uses the height of the ammonia absorption peaks for amount fraction calculation, which, due to the matrix gas dependent pressure broadening coefficients of the absorption lines, gives accurate results only in a specific matrix gas, for which the algorithm was developed. The evaluation algorithm developed in MetNH3 uses the integrated absorbance (area under the measured absorption lines), which is, according to equation (2), independent of the matrix gas. We note that the manufacturer recommends using the spectrometer in air matrix gas, where it indeed provides correct readings. However, we would like to emphasise that it is a notable restriction during calibration or validation of the spectrometer, since reference gas mixtures are often prepared in nitrogen matrix gas.
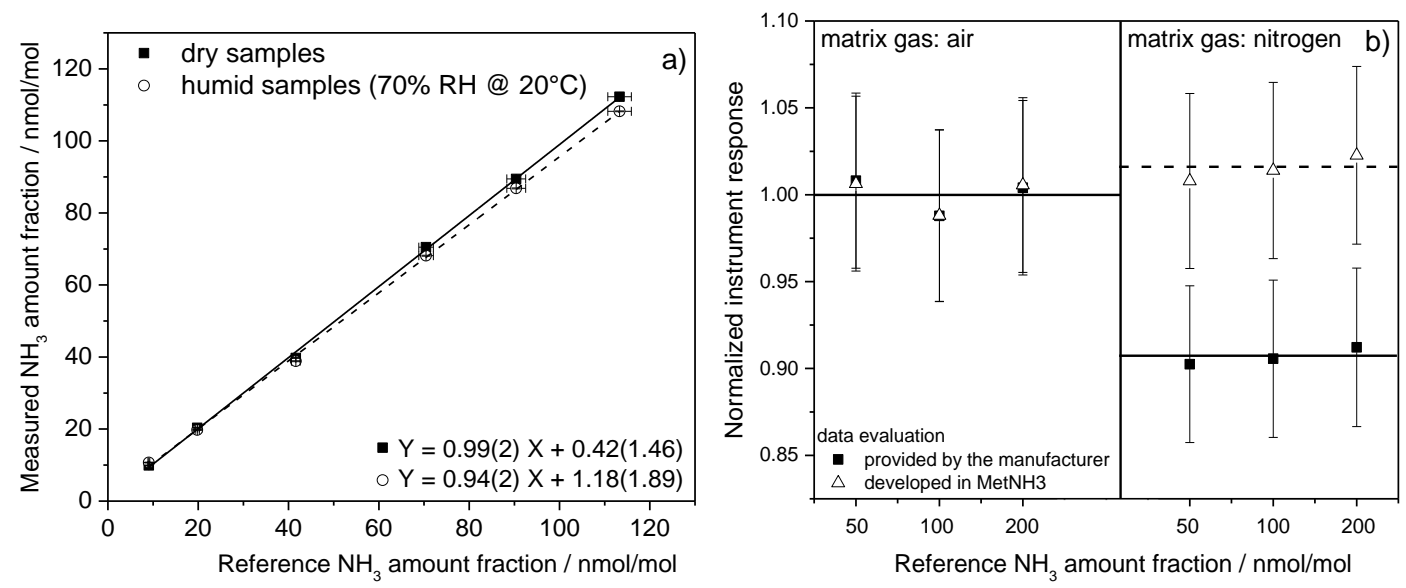

Figure 7: a) Calibration curves of a Picarro G2103 instrument using dry (closed squares) and humidified (open circles) test gases of ammonia in air, and b) measurement results in air and nitrogen matrix gases, obtained by the manufacturer's data evaluation algorithm (closed squares) and that developed in MetNH3 (open triangles),

582 where instrument response is normalized to the average of the ratio of the measured and reference ammonia 583 amount fractions in air and error bars refer to estimated expanded uncertainty.

Besides the spectroscopic aspects mentioned above, a possible bias and/or higher uncertainty introduced by sampling artefacts have to be investigated and quantified. In particular, response times of the analyzers are affected by adsorption-desorption processes, which have to be taken into account during measurements in rapidly changing gas mixtures. A significant decrease in the adsorption losses can be achieved by proper 
selection of the materials of the gas handling system, heating of the gas sampling lines and applying a higher flow rate. In our experiments Teflon inlet lines and particle filters are used with a flow rate of at least $1 \mathrm{slm}$. Response times of the CRDS spectrometer under such conditions were found to be in the range of minutes (10$90 \%$ response time below 1.5 minutes, 1-99\% response time below 30 minutes).

\section{Conclusions}

Previous studies revealed significant discrepancies between reference gas mixtures of $\mathrm{NH}_{3}$ in the $\mu \mathrm{mol} / \mathrm{mol}$ amount fraction range, as well as between amount fractions measured in the $\mathrm{nmol} / \mathrm{mol}$ range by different analytical techniques. The major reasons for this are the low ammonia amount fractions in ambient air, as well as the highly adsorptive and reactive nature of the ammonia molecule, which makes both the preparation of reference materials and accurate analytical measurements challenging. The MetNH3 project aims to improve the situation through developments in three major fields: 1) development of certified reference materials in cylinders and traceable dynamic gas mixture generators, 2) development and characterization of sampling-free and extractive spectroscopic instruments aiming to construct an optical transfer standard and 3) providing infrastructure for laboratory and field inter-comparison measurements to establish the link between highaccuracy metrological standards and field measurement methods. First results of the project have been described in this article. The first significant results have been achieved in two major fields: the study of adsorption of ammonia on different material surfaces, and the spectroscopic detection of ammonia by cavity ring-down spectroscopy.

Decantation studies carried out in cylinders showed that ammonia adsorption on the walls of stainless steel cylinders coated with SilcoNert 2000 is insignificant, even lower than the amount of adsorption observed in aluminium cylinders with Spectra Seal ${ }^{\mathrm{TM}}$ and Aculife $^{\mathrm{TM}}$ surface passivation treatments, which are usually applied for the preparation of commercial ammonia reference gas mixtures. Adsorption studies in dynamic systems showed similar results: SilcoNert 2000 coated stainless steel tubes showed (similarly to Teflon-PFA tubing) up to 10 times lower adsorption than stainless steel tubing with other surface treatments (Supelco and electro-polishing).

To improve accuracy and reliability of the spectroscopic detection of ammonia with a Picarro G2103 spectrometer, a novel data evaluation algorithm is being developed within the project. This algorithm is based on the determination of the integrated absorption coefficient by spectral fitting and calculation of the ammonia amount fraction according to the Beer-Lambert law. Two phenomena have been observed so far, where the novel algorithm might excel over the more simple evaluation algorithm provided by the spectrometer manufacturer. We have shown that dependence of the measured ammonia amount fraction on the matrix gas (which, e.g., leads to $10 \%$ bias when using nitrogen instead of air as matrix gas) can be eliminated using the novel algorithm. Cross-sensitivity to water vapour has also been observed, which leads to a few \% lower readings in gas samples with ambient humidity levels. Further development of the data evaluation algorithm to account for this cross-sensitivity is ongoing.

Research in further fields investigated by the MetNH3 project is progressing as well; however, first tangible results are expected later during the project. A sampling-free spectrometer based on an open multi-pass cell and a quantum cascade laser has been constructed and its metrological characterization is ongoing. It is 
expected to be the first sampling-free spectrometer providing traceable ammonia amount fraction results without the need for calibration using gas standards. Two dynamic reference gas generators are being developed, which will be able to provide traceable reference gas mixtures with $0.5-500 \mathrm{nmol} / \mathrm{mol}$ ammonia amount fractions with lower than $3 \%$ uncertainty (typical uncertainties in the $\mathrm{NH}_{3}$ amount fractions provided

630 by commercial generators are $>10 \%$ ). Two test facilities, an aerodynamic wind tunnel and a proficiency test

631 facility are being characterized. These facilities will provide the infrastructure for the inter-comparison of 632 ammonia analyzers and reference gases developed within the project, as well as for the testing and validation 633 of further devices and samplers.

\section{Acknowledgements}

The authors acknowledge financial support and collaboration in EMRP projects. The EMRP is jointly funded by the participating countries within EURAMET and the European Union.

\section{References}

638 [1] Stevens C J, Dupr C, Dorland E, Gaudnik C, Gowing D J G, Bleeker A, Diekmann M, Alard D, Bobbink R, Fowler D, Corcket E, Mountford J O, Vandvik V, Aarrestad P A, Muller S and Dise N B 2010 Nitrogen deposition threatens species richness of grasslands across Europe Environ. Pollut. 158 2940-5

[2] Sutton M A, Reis S and Baker S M H 2009 Atmospheric ammonia ed M A Sutton, S Reis and S M H Baker

643 [3] Sutton M A, Erisman J W, Dentener F and Möller D 2008 Ammonia in the environment: From ancient

[4] Air Pollution Information System, http://www.apis.ac.uk

[5] Protocol to the 1979 Convention on Long-range Transboundary Air Pollution to Abate Acidification , Eutrophication and Ground-Level Ozone, 1979, p. 1-94

[6] Decision 2012/12 Guidance for adjustments under the Gothenburg Protocol to emission reduction commitments or to inventories for the purposes of comparing total national emissions with them, 2012, p. 1-5

651 [7] UNECE 2001 Directive 2001/81/EC of the European Parliament and of the Council, p. 1-9

[8] European Comission 1992 Council Directive 92/43/EEC of 21 May 1992 on the conservation of natural habitats and of wild fauna and flora, p. 1-52

654 [9] European Monitoring and Evaluation Programme (EMEP), http://www.emep.int

655 [10] Lolkema D E, Noordijk H, Stolk A P, Hoogerbrugge R, van Zanten M C and van Pul W A J 2015 The Measuring Ammonia in Nature (MAN) network in the Netherlands Biogeosciences Discuss. 12 6115-46

[11] Bobrutzki K Von, Braban C F, Famulari D, Jones S K, Blackall T, Smith T E L, Blom M, Coe H, Gallagher M, Ghalaieny M, McGillen M R, Percival C J, Whitehead J D, Ellis R, Murphy J, Mohácsi Á, Pogány A, Junninen H, Rantanen S, Sutton M A and Nemitz E 2010 Field inter-comparison of eleven atmospheric ammonia measurement techniques Atmos. Meas. Tech. 3 91-112

[12] Norman M, Spirig C, Wolff V, Trebs I, Flechard C, Wisthaler a., Schnitzhofer R, Hansel a. and Neftel a. 2008 Intercomparison of ammonia measurement techniques at an intensively managed grassland site (Oensingen, Switzerland) Atmos. Chem. Phys. Discuss. 8 19791-818 
Guenther F R, Rhoderick G C, Konopelko L A and Kustikov Y A 2010 International Comparison CCQM K46 - Ammonia in Nitrogen Metrologia 4708023

[15] EMRP MetNH3 project, http://www.metnh3.eu

[16] 2008 JCGM 100:2008 Evaluation of measurement data - Guide to the expression of uncertainty in measurement (International Organization for Standardization)

[17] Pogány A, Balslev-harder D, Braban C F, Cassidy N, Ebert V, Ferracci V, Leuenberger D, Lüttschwager N, Martin N, Pascale C, Tiebe C, Twigg M M, Vaittinen O, Wijk J Van, Wirtz K and Niederhauser B 2015 Metrology for ammonia in ambient air - concept and first results of the EMRP project MetNH3 $17^{\text {th }}$ International Congress of Metrology pp 1-9

[18] ISO 6142:2006 Gas analysis. Preparation of calibration gas mixtures. Gravimetric method

[19] ISO 6145-10:2012-06, Gas analysis - Preparation of calibration gas mixtures using dynamic volumetric methods - Part 10: Permeation method.

[20] LNI Schmidlin SA, www.Inischmindlin.ch

[21] Owlstone Ltd., www.owlstonenanotech.com

[22] VICI AG International, www.vici.com

[23] Kin-Tek Laboratories Inc., www.kin-tek.com

[24] 2012 JCGM 200 : 2012 International vocabulary of metrology - Basic and general concepts and associated terms ( VIM) (International Organization for Standardization)

[25] Rothman LS, Gordon I E, Babikov Y, Barbe a., Chris Benner D, Bernath P F, Birk M, Bizzocchi L, Boudon V, Brown L R, Campargue a., Chance K, Cohen E a., Coudert L H, Devi V M, Drouin B J, Fayt a., Flaud JM, Gamache R R, Harrison J J, Hartmann J-M, Hill C, Hodges J T, Jacquemart D, Jolly a., Lamouroux J, Le Roy R J, Li G, Long D a., Lyulin O M, Mackie C J, Massie S T, Mikhailenko S, Müller H S P, Naumenko O V, Nikitin a. V, Orphal J, Perevalov V, Perrin a., Polovtseva E R, Richard C, Smith M a. H, Starikova E, Sung K, Tashkun S, Tennyson J, Toon G C, Tyuterev V G and Wagner G 2013 The HITRAN2012 molecular spectroscopic database J. Quant. Spectrosc. Radiat. Transf. 130 4-50

[26] Schilt S, Thévenaz L, Niklès M, Emmenegger L and Hüglin C 2004 Ammonia monitoring at trace level using photoacoustic spectroscopy in industrial and environmental applications Spectrochim. Acta - Part A Mol. Biomol. Spectrosc. $603259-68$

[27] Miller D J, Sun K, Tao L, Khan M a. and Zondlo M a. 2014 Open-path, quantum cascade-laser-based sensor for high-resolution atmospheric ammonia measurements Atmos. Meas. Tech. 7 81-93

[28] Volten H, Bergwerff J B, Haaima M, Lolkema D E, Berkhout a. J C, Van Der Hoff G R, Potma C J M, Wichink Kruit R J, Van Pul W a J and Swart D P J 2012 Two instruments based on differential optical absorption spectroscopy (DOAS) to measure accurate ammonia concentrations in the atmosphere Atmos. Meas. Tech. 5 413-27

[29] Owen K and Farooq A 2014 A calibration-free ammonia breath sensor using a quantum cascade laser with WMS 2f/1f Appl. Phys. B 116 371-83

[30] Pogány A, Wagner S, Werhahn O and Ebert V 2015 Development and Metrological Characterization of a Tunable Diode Laser Absorption Spectroscopy (TDLAS) Spectrometer for Simultaneous Absolute Measurement of Carbon Dioxide and Water Vapor Appl. Spectrosc. 69 257-68

[31] Buchholz B, Böse N and Ebert V 2014 Absolute validation of a diode laser hygrometer via intercomparison with the German national primary water vapor standard Appl. Phys. B 116 883-99

[32] Berglund M and Wieser M E 2011 Isotopic compositions of the elements 2009 (IUPAC Technical Report) Pure Appl. Chem. 83 397-410

[33] Owen K, Es-sebbar E T and Farooq A 2013 Measurements of $\mathrm{NH}_{3}$ linestrengths and collisional broadening coefficients in $\mathrm{N}_{2}, \mathrm{O}_{2}, \mathrm{CO}_{2}$, and $\mathrm{H}_{2} \mathrm{O}$ near $1103.46 \mathrm{~cm}^{-1} \mathrm{~J}$. Quant. SpectrosC. Radiat. Transf. $12156-68$

[34] Werhahn O, Brunzendorf J, Nwaboh J A, Serdyukov A, Werwein V and Ebert V 2014 Spectral reference 
line data relevant to remote sensing applications: a review and outline of the EUMETRISPEC project

[35] Pogány A, Ott O, Werhahn O and Ebert V 2013 Towards traceability in $\mathrm{CO}_{2}$ line strength measurements

[36] Pogány A, Klein A and Ebert V 2015 Measurement of water vapor line strengths in the 1.4-2.7 $\mu \mathrm{m}$ range by tunable diode laser absorption spectroscopy J. Quant. Spectrosc. Radiat. Transf. 165 108-22

[37] Ortwein P, Woiwode W, Wagner S, Gisi M and Ebert V 2009 Laser-based measurements of line strength, self- and pressure-broadening coefficients of the $\mathrm{H}^{35} \mathrm{Cl} \mathrm{R}(3)$ absorption line in the first overtone region for pressures up to $1 \mathrm{MPa}$ Appl. Phys. B 100 341-7

724 [38] Picarro Inc., www.picarro.com

[39] Wyers G P, Otjes R P and Slanina J 1993 A continuous-flow denuder for the measurement of ambient concetrations and surface-exchange fluxes of ammonia Atmos. Environ. 27A 2085-90

[40] Barbiere M, Stummer V, Lagler F and Mücke H-G 2013 Evaluation of the Laboratory Comparison Exercise for $\mathrm{NO}, \mathrm{NO}_{2}, \mathrm{SO}_{2}, \mathrm{CO}$ and $\mathrm{O}_{3}$ Langen (D) $1^{\text {st }}-6^{\text {th }}$ September 2013 EC Harmonization Program for Air Quality Measurements (Luxembourg)

[41] Vaittinen O, Metsälä M, Persijn S, Vainio M and Halonen L 2013 Adsorption of ammonia on treated stainless steel and polymer surfaces Appl. Phys. B 115 185-96

[42] Mukhtar S, Rose A J, Capareda S C, Boriack C N, Lacey R E, Shaw B W and Parnell C B 2003 Assessment of ammonia adsorption onto teflon and LDPE tubing Agric. Eng. Int. CIGR J. V BC 03012

[43] Henningsen J and Melander N 1997 Sensitive measurement of adsorption dynamics with nonresonant gas phase photoacoustics Appl. Opt. 36 7037-45

[44] SilcoTek Inc., www.silcotek.com

[45] Roscioli J R, Zahniser M S, Nelson D D, Herndon S C and Kolb C E 2015 New Approaches to Measuring Sticky Molecules: Improvement of Instrumental Response Times Using Active Passivation J. Phys. Chem.

[46] Ellis R a., Murphy J G, Pattey E, Van Haarlem R, O'Brien J M and Herndon S C 2010 Characterizing a Quantum Cascade Tunable Infrared Laser Differential Absorption Spectrometer (QC-TILDAS) for measurements of atmospheric ammonia Atmos. Meas. Tech. 3 397-406

743 [47] Spectra-Seal, Registration Nr. 3853813, 2010, BOC Limited

744 [48] Aculife, Registration Nr. 4104439, 2012, Air Liquide America Specialty Gases LLC

[49] Buchholz B, Kühnreich B, Smit H G J and Ebert V 2012 Validation of an extractive, airborne, compact TDL spectrometer for atmospheric humidity sensing by blind intercomparison Appl. Phys. B 110 249-62

[50] Nielsen L 2002 Evaluation of measurements by the method of least squares Algorithms for Approximation IV ed J Levesley, I J Andreson and J C Mason (University of Huddersfield) pp 170-86

[51] Pogány A, Werhahn O, Ebert V 2016 High-accuracy ammonia line intensity measurements at $1.5 \mathrm{~mm}$ Imaging and Applied Optics 2016, OSA technical Digest (online), Optical Society of America, JT3A.15

[52] Schilt S 2010 Impact of water vapor on $1.51 \mu \mathrm{m}$ ammonia absorption features used in trace gas sensing applications Appl. Phys. B Lasers Opt. 100 349-59 